\title{
Biossegurança em Odontologia: conduta dos estudantes antes e após uma ação educativa
}

\author{
Amanda Lívia Lopes*; Lorrany Gabriela Rodrigues**; Lívia Guimarães Zina***; Andréa Clemente \\ Palmier***; Fabiana Vargas-Ferreira***; Mauro Henrique Nogueira Guimarães de Abreu***; Mara \\ Vasconcelos $* * *$
}

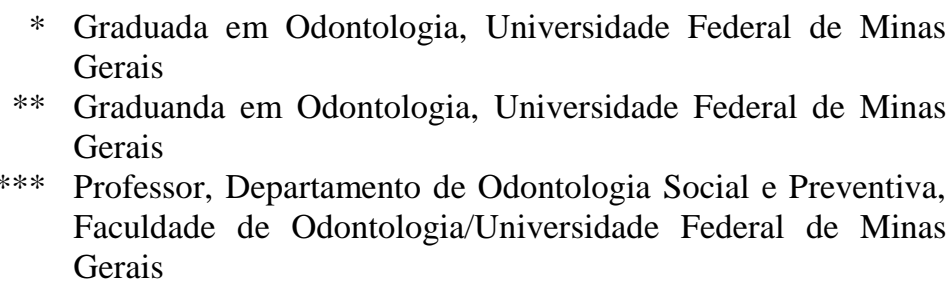

Recebido em 04/12/2018. Aprovado em 10/05/2019.

\begin{abstract}
RESUMO
O objetivo do estudo foi avaliar o conhecimento e a adesão dos estudantes de graduação em Odontologia da Universidade Federal de Minas Gerais quanto às normas de biossegurança e controle da infecção. Trata-se de um estudo transversal descritivo realizado com alunos do $4^{\circ}$ ao $10^{\circ}$ período, matriculados no segundo semestre de 2017. Houve uma intervenção que buscou reforçar os conhecimentos de biossegurança por meio da distribuição de folhetos informativos aos estudantes e afixação de pôsteres em locais de maior circulação. Foram coletadas informações sociodemográficas e relativas à biossegurança antes e após a intervenção, por meio de um questionário validado. Foram realizadas análises descritivas e bivariada por meio do teste qui-quadrado. A amostra constituiu de 653 estudantes, a maioria do sexo feminino, cursando entre o $7^{\circ}$ e o $10^{\circ}$ períodos, com média de idade de 22,6 anos. Quanto à proteção mecânica dos instrumentos de trabalho, tanto antes quanto após a ação, mais de $80 \%$ responderam sempre utilizar barreiras. Houve redução das frequências de desinfecção do ambiente e uso de equipamentos de proteção individual. A frequência de lavagem dos instrumentais aumentou de 95,4\% para 96,6\% após a intervenção, enquanto a esterilização reduziu de $100 \%$ para $98,8 \%$. Houve associação entre o uso de equipamentos de proteção individual com o sexo feminino e os períodos iniciais do curso $(\mathrm{p}<0,001)$. Conclui-se que os estudantes do sexo feminino e dos períodos iniciais aderem com maior frequência às normas de biossegurança. Os conhecimentos sobre biossegurança não foram satisfatórios para o controle da infecção, mesmo após a ação educativa.
\end{abstract}

Descritores: Controle de Infecções. Contenção de Riscos Biológicos. Ensino. Esterilização. Equipamento de Proteção Individual.

\section{INTRODUÇÃO}

A Biossegurança é um conjunto de ações que contribui para a prevenção, diminuição ou elimina- ção dos riscos inerentes à prática profissional, principalmente, na área da saúde. É de suma importância que os profissionais da Odontologia 
atualizem seus conhecimentos sobre procedimentos e normas de biossegurança. Sua aplicação envolve conhecimento, responsabilidade, determinação, organização e disciplina $^{1}$.

Visando reduzir e eliminar os riscos que o ambiente odontológico traz, a biossegurança deve ser adotada tanto pelos profissionais quanto pelos acadêmicos nas instituições de ensino de Odontologia, oferecendo maior segurança e conforto durante a execução das atividades clínicas $^{2}$.

Os trabalhadores em saúde e estudantes estão expostos constantemente a riscos ocupacionais, sejam químicos, físicos, mecânicos ou biológicos, e as lesões percutâneas que podem ocorrer durante $o$ atendimento podem vir a interferir diretamente no seu processo laboral ${ }^{3}$.

O risco de contaminação pode se tornar maior quando o profissional ou estudante negligencia os protocolos de biossegurança. Para interromper a contaminação cruzada é necessária a adoção de medidas que evitem a transmissão de microrganismos patogênicos. É fundamental que os profissionais e estudantes da área da saúde tenham conhecimento suficiente sobre as medidas e práticas de biossegurança para que haja diminuição dos riscos inerentes ao ambiente de atuação. Qualquer medida que limite a ocorrência de incidentes deve ser adotada, o que reduz os riscos à saúde do paciente e do profissional ${ }^{4,5}$.

Apesar de haver medidas que mantêm seguros o profissional e o paciente, ainda há barreiras que impedem o correto cumprimento das normas de biossegurança. O desconhecimento, os erros sobre métodos de esterilização, a resistência bacteriana e de vários tipos de vírus, além da ausência de cuidado dos profissionais com situações de risco contribuem para o aumento do número de casos de infecções ${ }^{6}$.

Os conhecimentos sobre biossegurança, a experiência quanto ao uso consciente de equipamentos de proteção individual (EPI) e prevenção de acidentes ocupacionais aumentam no decorrer dos períodos cursados. Dados obtidos em um estudo com estudantes matriculados no primeiro, quinto e últimos períodos de três faculdades, ressaltam a necessidade de se promover um processo formativo sobre biossegurança desde os primeiros períodos do curso, buscando a construção de uma sólida base teórica que garanta aos estudantes uma entrada nas atividades clínicas com maior confiança ${ }^{2,7}$.

Sendo assim, o objetivo do presente trabalho foi avaliar o conhecimento e adesão dos alunos de Graduação em Odontologia quanto às normas de biossegurança e controle da infecção.

\section{MATERIAIS E MÉTODOS}

Trata-se de um estudo que envolveu estudantes da Faculdade de Odontologia da Universidade Federal de Minas Gerais (UFMG) matriculados do $4^{\circ}$ ao $10^{\circ}$ período, no segundo semestre de 2017.

Houve uma intervenção que buscou reforçar os conhecimentos de biossegurança por meio da distribuição de folhetos informativos aos alunos antes do início do atendimento odontológico e afixação de pôsteres em locais de maior circulação. O documento continha as normas corretas de biossegurança em relação aos procedimentos e condutas frente à utilização dos EPI, desinfecção do ambiente de trabalho, lavagem, esterilização e armazenamento de instrumentais.

Foram coletadas informações socioeconômicas e relativas à Biossegurança, por meio de um questionário adaptado de Martins (2016) ${ }^{8}$ antes da ação e após três meses. As variáveis incluíram sexo e período, questões sobre proteção pessoal, desinfecção do ambiente de trabalho, lavagem de instrumental, atitudes e conhecimentos. As respostas foram organizadas em escala tipo Likert.

As análises foram realizadas no software SPSS, versão 19. Foi realizada análise descritiva 
por meio de frequências absoluta (n) e relativa (\%). Para a análise bivariada foi usado o teste quiquadrado $(\mathrm{p}<0,05)$.

Esta pesquisa foi aprovada pelo Comitê de Ética da UFMG (Parecer $n^{\circ}$ 1.575.644, CAAE: 42723315.3.0000.5149).

\section{RESULTADOS}

A amostra consistiu, respectivamente, de 323 e 330, estudantes de Graduação em Odontologia, antes e após intervenção. Observou-se que mais de $70 \%$ dos estudantes eram do sexo feminino e mais da metade estavam entre o $7^{\circ}$ e $10^{\circ}$ períodos (tabela 1). Dentre os estudantes participantes, antes e após a ação, a média (desvio-padrão) da idade foi similar entre os grupos, 22,6 $( \pm 2,62)$ anos, variando de 19 a 49 anos.

A tabela 2 descreve as características relacionadas à proteção individual, sendo que o uso da máscara pós-ação foi relatado pela quase totalidade dos estudantes. Entretanto, antes da intervenção, 32,0\% faziam uso dos óculos de proteção às vezes/nunca e após a ação não houve melhora do quadro $(35,0 \%)$.

Tabela 1. Características dos estudantes do curso de Odontologia da Universidade Federal de Minas Gerais, antes $(n=323)$ e após ação $(n=330)$

\begin{tabular}{lcccc}
\hline \multirow{2}{*}{ Variáveis } & \multicolumn{2}{c}{ Antes da ação } & \multicolumn{2}{c}{ Após a ação } \\
& $\mathrm{n}$ & $\%$ & $\mathrm{n}$ & $\%$ \\
\hline $\begin{array}{l}\text { Sexo } \\
\text { Masculino }\end{array}$ & 69 & 21,4 & 75 & 23,2 \\
$\quad$ Feminino & 254 & 78,6 & 248 & 76,8 \\
Período (semestre) & & & & \\
$4^{\circ}$ a $6^{\circ}$ & 153 & 47,4 & 147 & 45,5 \\
$7^{\circ}$ a $10^{\circ}$ & 170 & 52,6 & 176 & 54,4 \\
\hline
\end{tabular}

Tabela 2. Características dos estudantes do curso de Odontologia da Universidade Federal de Minas Gerais em relação aos equipamentos de proteção individual antes $(\mathrm{n}=323)$ e após ação $(\mathrm{n}=330)$

\begin{tabular}{lcccc}
\hline \multirow{2}{*}{ Variáveis } & \multicolumn{2}{c}{ Antes da ação } & \multicolumn{2}{c}{ Após a ação } \\
& $\mathrm{n}$ & $\%$ & $\mathrm{n}$ & $\%$ \\
\hline Uso de Máscara & & & & \\
$\quad$ Sempre & 314 & 97,0 & 324 & 98,2 \\
$\quad$ Às vezes / Nunca & 9 & 3,0 & 6 & 1,8 \\
Uso de Óculos & & & & \\
$\quad$ Sempre & 219 & 68,0 & 209 & 65,0 \\
$\quad$ Às vezes / Nunca & 104 & 32,0 & 113 & 35,0 \\
Uso de Gorro & & & & \\
$\quad$ Sempre & 303 & 94,0 & 311 & 94,2 \\
$\quad$ Às vezes / Nunca & 20 & 6,0 & 19 & 5,8 \\
\hline
\end{tabular}


Em relação ao ambiente de trabalho, a frequência da desinfecção da peça de mão às vezes/nunca foi relatada por 5,9\% antes e após a ação houve uma redução nesta frequência (4,6\%). Em contrapartida, a não desinfecção da seringa tríplice ou sua pouca frequência (às vezes) foi reportada mais de $26,0 \%$ dos estudantes (tabela 3 ).

No que se refere à proteção mecânica dos instrumentos de trabalho, antes da ação, 87,6\% faziam isso sempre, após intervenção este número baixou para $84,0 \%$. Para a peça de mão essa diminuição se repetiu, antes $74,3 \%$ protegiam-na e após, apenas 69,0\%. Sobre a seringa tríplice, antes da intervenção a frequência sempre foi relatada por mais de $97,8 \%$ dos estudantes e após a intervenção 95,1\% ainda mantinham esta frequência (tabela 4).

Tabela 3. Características dos estudantes do curso de Odontologia da UFMG em relação aos procedimentos de desinfecção do ambiente de trabalho antes $(n=323)$ e após ação $(n=330)$

\begin{tabular}{|c|c|c|c|c|}
\hline \multirow{2}{*}{ Variáveis } & \multicolumn{2}{|c|}{ Antes da Ação } & \multicolumn{2}{|c|}{ Após a Ação } \\
\hline & $\mathrm{n}$ & $\%$ & $\mathrm{n}$ & $\%$ \\
\hline \multicolumn{5}{|c|}{ Realiza desinfecção das superfícies antes do atendimento } \\
\hline Sempre & 258 & 79,9 & 235 & 71,2 \\
\hline Às vezes / Nunca & 65 & 20,1 & 95 & 28,8 \\
\hline \multicolumn{5}{|c|}{ Realiza desinfecção do refletor } \\
\hline Sempre & 235 & 72,8 & 230 & 70,8 \\
\hline Às vezes / Nunca & 88 & 27,2 & 95 & 29,2 \\
\hline \multicolumn{5}{|c|}{ Realização desinfecção da peça de mão } \\
\hline Sempre & 304 & 94,1 & 314 & 95,4 \\
\hline Às vezes / Nunca & 19 & 5,9 & 15 & 4,6 \\
\hline \multicolumn{5}{|c|}{ Realiza desinfecção da cadeira } \\
\hline Sempre & 312 & 96,6 & 306 & 92,7 \\
\hline Às vezes / Nunca & 11 & 3,4 & 24 & 7,3 \\
\hline \multicolumn{5}{|c|}{ Realiza desinfecção da Seringa Tríplice } \\
\hline Sempre & 247 & 76,5 & 243 & 73,9 \\
\hline Às vezes / Nunca & 76 & 23,5 & 86 & 26,1 \\
\hline \multicolumn{5}{|c|}{ Realiza desinfecção da cuspideira } \\
\hline Sempre & 77 & 23,8 & 59 & 18,2 \\
\hline Às vezes / Nunca & 246 & 76,2 & 266 & 81,8 \\
\hline \multicolumn{5}{|c|}{ Realiza desinfecção da mesa de instrumental } \\
\hline Sempre & 309 & 95,7 & 312 & 94,8 \\
\hline Às vezes / Nunca & 14 & 4,3 & 17 & 5,2 \\
\hline
\end{tabular}


Tabela 4. Características dos estudantes do curso de Odontologia da UFMG em relação à proteção mecânica dos instrumentais antes $(n=323)$ e após ação $(n=330)$.

\begin{tabular}{|c|c|c|c|c|}
\hline \multirow{2}{*}{ Variáveis } & \multicolumn{2}{|c|}{ Antes da Ação } & \multicolumn{2}{|c|}{ Após a Ação } \\
\hline & $\mathrm{n}$ & $\%$ & $\mathrm{n}$ & $\%$ \\
\hline \multicolumn{5}{|c|}{ Utiliza barreira mecânica nas superfícies } \\
\hline Sempre & 283 & 87,6 & 273 & 84,0 \\
\hline Às vezes / Nunca & 40 & 12,4 & 52 & 16,0 \\
\hline \multicolumn{5}{|c|}{ Utiliza barreira mecânica no refletor } \\
\hline Sempre & 285 & 88,2 & 304 & 93,5 \\
\hline Às vezes / Nunca & 38 & 11,8 & 21 & 6,5 \\
\hline \multicolumn{5}{|c|}{ Utiliza barreira mecânica na peça de mão } \\
\hline Sempre & 240 & 74,3 & 225 & 69,0 \\
\hline Às vezes / Nunca & 83 & 25,7 & 101 & 31,0 \\
\hline \multicolumn{5}{|c|}{ Utiliza barreira mecânica na cadeira } \\
\hline Sempre & 310 & 96,0 & 317 & 97,2 \\
\hline Às vezes / Nunca & 13 & 4,0 & 9 & 2,8 \\
\hline \multicolumn{5}{|c|}{ Utiliza barreira mecânica na seringa tríplice } \\
\hline Sempre & 315 & 97,8 & 310 & 95,1 \\
\hline Às vezes / Nunca & 7 & 2,2 & 16 & 4,9 \\
\hline \multicolumn{5}{|c|}{ Utiliza barreira mecânica na mesa de instrumentais } \\
\hline Sempre & 269 & 83,3 & 273 & 83,7 \\
\hline Às vezes / Nunca & 54 & 16,7 & 53 & 16,3 \\
\hline \multicolumn{5}{|c|}{ Substitui as barreiras mecânicas entre os atendimentos } \\
\hline Sempre & 288 & 89,2 & 277 & 85,0 \\
\hline Às vezes / Nunca & 35 & 10,8 & 49 & 15,0 \\
\hline \multicolumn{5}{|c|}{ Após finalização de atendimento, retira as barreiras de proteção } \\
\hline Sempre & 307 & 95,1 & 309 & 95,1 \\
\hline Às vezes / Nunca & 16 & 4,9 & 16 & 4,9 \\
\hline
\end{tabular}

A tabela 5 descreve a frequência de lavagem e esterilização dos instrumentos, que foi realizada sempre por $95,4 \%$ dos estudantes antes da ação e após o número aumentou para $96,6 \%$, não atingindo os $100,0 \%$ preconizados. Em relação à esterilização, antes da ação todos os estudantes faziam isso sempre antes do atendimento. Após a ação, 4 estudantes relataram não a realizar sempre.

O uso de EPI sempre, antes e após a ação foi de $65,6 \%$ e 62,3\%, respectivamente. Antes da ação, o desfecho "sempre" foi associado com sexo $(p<0,001)$ e período $(p<0,001)$. Estudantes do sexo feminino apresentaram maior uso de EPI $(71,3 \%)$ comparadas aos indivíduos do sexo masculino (44,9\%). Em relação ao período, os estudantes do $4^{\mathrm{o}}$ semestre apresentaram maior frequência de uso de EPI comparados aos do último semestre (73,9\% e $37,5 \%$, respectivamente) (tabela 6 ).

Antes da intervenção, 95,7\% dos estudantes do $4^{\circ}$ período faziam proteção da peça de mão e no último semestre, somente $67,5 \%$ faziam isso $(p<0,001)$. Após a intervenção, a frequência do uso de proteção da peça de mão diminui à medida que os estudantes avançavam no curso (tabela 7).

Em relação à proteção da seringa tríplice, antes da intervenção, todos os alunos do $4^{\circ}$ período usavam a proteção e no último semestre a frequência reduziu para 95,0\%. Após a intervenção, a situação foi a mesma $(p<0,001)$ (tabela 8). 
Tabela 5. Características dos estudantes do curso de Odontologia da UFMG em relação à lavagem dos instrumentais e esterilização antes $(n=323)$ e após ação $(n=330)$

\begin{tabular}{|c|c|c|c|c|}
\hline \multirow{2}{*}{ Variáveis } & \multicolumn{2}{|c|}{ Antes da Ação } & \multicolumn{2}{|c|}{ Após a Ação } \\
\hline & $\mathrm{n}$ & $\%$ & $\mathrm{n}$ & $\%$ \\
\hline \multicolumn{5}{|c|}{ Realiza lavagem antes da esterilização } \\
\hline Sempre & 308 & 95,4 & 315 & 96,6 \\
\hline Às vezes / Nunca & 15 & 4,6 & 11 & 3,4 \\
\hline \multicolumn{5}{|c|}{ Realiza desinfecção do instrumental antes de lavar } \\
\hline Sempre & 249 & 77,1 & 160 & 49,5 \\
\hline Às vezes / Nunca & 74 & 22,9 & 163 & 50,5 \\
\hline \multicolumn{5}{|c|}{ Esteriliza o material antes do atendimento } \\
\hline Sempre & 323 & 100,0 & 322 & 98,8 \\
\hline Às vezes / Nunca & 0 & 0 & 4 & 1,2 \\
\hline
\end{tabular}

Tabela 6. Associação entre o uso de máscara, gorro e óculos (EPI) antes e após a ação e variáveis independentes (sexo e período) de estudantes do Curso de Odontologia da UFMG

\begin{tabular}{|c|c|c|c|c|c|c|c|c|}
\hline \multirow[b]{2}{*}{ Variáveis } & \multirow[b]{2}{*}{$\mathrm{n}$} & \multicolumn{2}{|c|}{ EPI antes } & \multirow[t]{2}{*}{$\mathbf{p}$} & \multicolumn{3}{|c|}{ EPI após } & \multirow[t]{2}{*}{$\mathbf{p}$} \\
\hline & & $\begin{array}{c}\text { Sempre } \\
\mathrm{n}(\%)\end{array}$ & $\begin{array}{c}\text { Às vezes/Nunca } \\
\mathrm{n}(\%)\end{array}$ & & $\mathrm{n}^{*}$ & $\begin{array}{c}\text { Sempre } \\
\mathrm{n}(\%)\end{array}$ & $\begin{array}{c}\text { Às vezes/Nunca } \\
\mathrm{n}(\%)\end{array}$ & \\
\hline & & $212(65,6)$ & $111(34,4)$ & & & $201(62,3)$ & $121(37,7)$ & \\
\hline $\begin{array}{l}\text { Sexo } \\
\text { Feminino }\end{array}$ & 254 & $181(71,3)$ & $73(28,7)$ & $<0,001$ & 253 & $166(65,6)$ & $87(34,4)$ & 0,024 \\
\hline Masculino & 69 & $31(44,9)$ & $38(55,1)$ & & 77 & $39(51,3)$ & $37(48,7)$ & \\
\hline $\begin{array}{l}\text { Período } \\
4^{\circ}\end{array}$ & 46 & $34(73,9)$ & $12(26,1)$ & $<0,001$ & 42 & $33(78,6)$ & $9(21,4)$ & 0,012 \\
\hline $5^{\circ}$ & 50 & $40(80,0)$ & $10(20,0)$ & & 51 & $34(66,7)$ & $17(33,3)$ & \\
\hline $6^{\circ}$ & 57 & $45(78,9)$ & $12(21,1)$ & & 54 & $39(72,2)$ & $15(27,8)$ & \\
\hline $7^{\circ}$ & 42 & $27(64,3)$ & $15(35,7)$ & & 47 & $31(66,0)$ & $16(34,0)$ & \\
\hline $8^{\circ}$ & 50 & $26(52,0)$ & $24(48,0)$ & & 44 & $23(52,3)$ & $21(47,7)$ & \\
\hline $9^{\circ}$ & 38 & $25(65,8)$ & $13(34,2)$ & & 58 & $30(51,7)$ & $28(48,3)$ & \\
\hline $10^{\circ}$ & 40 & $15(37,5)$ & $25(62,5)$ & & 33 & $15(45,5)$ & $18(54,5)$ & \\
\hline
\end{tabular}

*Variável com perda de informações 
Tabela 7. Associação entre proteção da peça de mão antes e após a ação e variáveis independentes (sexo e período) de estudantes do Curso de Odontologia da UFMG

\begin{tabular}{|c|c|c|c|c|c|c|c|c|}
\hline \multirow{2}{*}{ Variáveis } & \multicolumn{3}{|c|}{$\begin{array}{l}\text { Proteção da peça de } \\
\text { mão antes }\end{array}$} & \multirow[t]{2}{*}{$\mathrm{p}$} & \multicolumn{3}{|c|}{$\begin{array}{l}\text { Proteção da peça de } \\
\text { mão após }\end{array}$} & \multirow[t]{2}{*}{$\mathrm{p}$} \\
\hline & $\mathrm{n}$ & $\begin{array}{c}\text { Não } \\
\text { n (\%) }\end{array}$ & $\begin{array}{c}\text { Sim } \\
\mathrm{n}(\%)\end{array}$ & & $\mathrm{n}^{*}$ & $\begin{array}{l}\text { Não } \\
\text { n }(\%)\end{array}$ & $\begin{array}{l}\operatorname{Sim} \\
\mathrm{n}(\%)\end{array}$ & \\
\hline Sexo & & & & 0,481 & & & & 0,946 \\
\hline Feminino & 254 & $63(24,8)$ & $191(75,2)$ & & 251 & $78(31,1)$ & $173(68,9)$ & \\
\hline Masculino & 69 & $20(29,0)$ & $49(71,0)$ & & 75 & $23(30,7)$ & $52(69,3)$ & \\
\hline Período & & & & $<0,001$ & & & & $<0,001$ \\
\hline $4^{\circ}$ & 46 & $2(4,3)$ & $44(95,7)$ & & 42 & $1(2,4)$ & $41(97,6)$ & \\
\hline $5^{\circ}$ & 50 & $4(8,0)$ & $46(92,0)$ & & 50 & $7(14,0)$ & $43(86,0)$ & \\
\hline $6^{\circ}$ & 57 & $16(28,1)$ & $41(71,9)$ & & 53 & $9(17,0)$ & $44(83,0)$ & \\
\hline $7^{\circ}$ & 42 & $7(16,7)$ & $35(83,3)$ & & 48 & $20(41,7)$ & $28(58,3)$ & \\
\hline $8^{\circ}$ & 50 & $21(42,0)$ & $29(58,0)$ & & 44 & $20(45,5)$ & $24(54,5)$ & \\
\hline $9^{\circ}$ & 38 & $20(52,6)$ & $18(47,4)$ & & 58 & $26(44,8)$ & $32(55,2)$ & \\
\hline $10^{\circ}$ & 40 & $13(32,5)$ & $27(67,5)$ & & 31 & $18(58,1)$ & $13(41,9)$ & \\
\hline
\end{tabular}

Tabela 8. Associação entre proteção da seringa tríplice antes e após a ação e variáveis independentes (sexo e período) de estudantes do Curso de Odontologia da UFMG

\begin{tabular}{|c|c|c|c|c|c|c|c|c|}
\hline \multirow{2}{*}{ Variáveis } & \multirow[b]{2}{*}{$\mathrm{n}$} & \multicolumn{2}{|c|}{$\begin{array}{l}\text { Proteção da seringa } \\
\text { tríplice antes }\end{array}$} & \multirow[t]{2}{*}{$\mathrm{p}$} & \multirow[b]{2}{*}{$\mathrm{n}^{*}$} & \multicolumn{2}{|c|}{$\begin{array}{l}\text { Proteção da seringa } \\
\text { tríplice após }\end{array}$} & \multirow[t]{2}{*}{$\mathrm{p}$} \\
\hline & & $\begin{array}{c}\text { Não } \\
\text { n (\%) }\end{array}$ & $\begin{array}{c}\operatorname{Sim} \\
\mathrm{n}(\%)\end{array}$ & & & $\begin{array}{l}\text { Não } \\
\mathrm{n}(\%)\end{array}$ & $\begin{array}{l}\mathrm{Sim} \\
\mathrm{n}(\%)\end{array}$ & \\
\hline Sexo & & & & $<0,001$ & & & & 0,846 \\
\hline Feminino & 253 & $2(0,8)$ & $251(99,2)$ & & 251 & $12(4,8)$ & $239(95,2)$ & \\
\hline Masculino & 69 & $5(7,2)$ & $64(92,8)$ & & 75 & $4(5,3)$ & $71(94,7)$ & \\
\hline Período & & & & 0,031 & & & & $<0,001$ \\
\hline $4^{\circ}$ & 46 & $0(0)$ & $46(100,0)$ & & 42 & $0(0)$ & $42(100,0)$ & \\
\hline $5^{\circ}$ & 50 & $0(0)$ & $50(100,0)$ & & 50 & $0(0)$ & $50(100,0)$ & \\
\hline $6^{\circ}$ & 57 & $0(0)$ & $57(100,0)$ & & 53 & $0(0)$ & $53(100,0)$ & \\
\hline $7^{\circ}$ & 42 & $0(0)$ & $42(100,0)$ & & 48 & $4(8,3)$ & $44(91,7)$ & \\
\hline $8^{\circ}$ & 50 & $4(8,0)$ & $46(92,0)$ & & 44 & $3(6,8)$ & $41(93,2)$ & \\
\hline $9^{\circ}$ & 37 & $1(2,7)$ & $36(97,3)$ & & 58 & $3(5,2)$ & $55(94,8)$ & \\
\hline $10^{\circ}$ & 40 & $2(2,5)$ & $38(95,0)$ & & 31 & $6(19,4)$ & $25(80,6)$ & \\
\hline
\end{tabular}

Quanto ao conhecimento sobre responderam que era a faculdade, resposta biossegurança, antes da ação 53,6\% responderam mantida após a intervenção por 297 (91,4\%) dos que tinham e, após a ação houve redução 325 entrevistados. Antes da intervenção 85,5\% considerável $(44,0 \%)$.

No que se refere à principal fonte de conhecimento sobre biossegurança, antes da ação, dos 323 entrevistados, 287 (88,9\%) 76,8\% dos entrevistados. 


\section{DISCUSSÃO}

Esse estudo permitiu várias análises e optouse por detalhar os procedimentos que mais poderiam impactar a qualidade da biossegurança. Responderam 330 estudantes do $4^{\circ}$ ao $10^{\circ}$ período. Observou-se que mais de $70 \%$ eram do sexo feminino. A predominância do sexo feminino nos cursos de Odontologia também está demonstrada em estudos realizados em outras instituições de ensino brasileiras ${ }^{4,8-10}$.

Em relação ao uso de EPI, a maioria dos estudantes sempre faz uso de máscara $(98,2 \%)$ e gorro $(94,2 \%)$, porém apenas $65,0 \%$ faz sempre o uso dos óculos de proteção. Os resultados encontrados são semelhantes a outros estudos ${ }^{1,11-13}$. $\mathrm{O}$ uso de EPI é obrigatório para todos os atendimentos, procedimentos de limpeza do ambiente e reprocessamento de artigos, além de constituir barreira protetora eficiente ${ }^{14,15}$. Estudantes do sexo feminino utilizam mais EPI do que o sexo masculino, de acordo com estudo realizado na mesma instituição ${ }^{8}$. Este fato pode estar relacionado com o medo de ferirem os pacientes ou a si mesmos, por isso respeitam mais as normas de biossegurança ${ }^{16}$.

Sobre a desinfecção das superfícies do ambiente de trabalho, antes da ação 79,9\% dos estudantes a realizavam e após somente $71,2 \%$. Em estudo no curso de Odontologia da Universidade Federal da Paraíba, foi verificada uma frequência inferior ao deste estudo ${ }^{4}$. A frequência de desinfecção da peça de mão era realizada por 94,1\% dos estudantes antes da ação e 95,4\% após. Resultado semelhante foi encontrado em estudo realizado com estudantes de graduação de outra faculdade, na qual $97,1 \%$ dos pesquisados costumavam desinfetar a caneta entre os atendimentos ${ }^{17}$. Em relação à seringa tríplice, antes da ação 76,5\% sempre realizavam a desinfecção e após $73,9 \%$. A peça de mão/alta rotação e a seringa tríplice apresentam uma elevada fonte de contaminação, o que pode ser explicado pelo seu maior contato com a cavidade oral durante os procedimentos $^{17,18}$. A norma preconiza que a desinfecção deve ser realizada com álcool 70 (considerada nível médio), sendo esse produto tuberculicida, bactericida, fungicida e viruscida, porém não é esporicida ${ }^{19}$.

Quanto à proteção mecânica dos instrumentos de trabalho, antes da ação 87,6\% dos estudantes faziam sempre e, após, apenas 84,0\%. Para a peça de mão essa diminuição se repetiu, antes 74,3\% protegiam-na e após, apenas $69,0 \%$. Sobre a seringa tríplice, antes da ação, 97,8\% dos estudantes sempre faziam e após a ação, 95,1\%. Resultados semelhantes foram encontrados no curso de Odontologia da Universidade Federal da Paraíba, em que 73,5\% dos estudantes sempre realizavam a proteção mecânica, e a peça de mão e seringa tríplice foram alguns dos itens menos protegidos ${ }^{4}$. Em relação ao período dos estudantes, antes da ação $95,7 \%$ dos estudantes do $4^{\circ}$ período faziam proteção da peça de mão e no último semestre, somente $67,5 \%$ faziam esse procedimento. Sobre a seringa tríplice, antes $100 \%$ dos alunos do $4^{\circ}$ período utilizavam proteção e no último semestre, a frequência se reduziu para $95,0 \%$. Após a ação educativa, a frequência do uso de proteção da peça de mão e da seringa tríplice, diminuiu à medida que os estudantes avançaram no curso. Em contrapartida, um estudo observou que o comportamento dos alunos do $5^{\circ}$ período para peças de mão e seringa tríplice, foi pior que os dos demais estudantes ${ }^{4}$.

A frequência de lavagem foi sempre por 95,4\% dos estudantes antes da ação, após aumentou para 96,6\%. Pimentel et al., (2012) observaram que a lavagem prévia à esterilização era realizada por $86,2 \%$ com frequência e que $10,3 \%$ faziam quando o material estava visivelmente sujo.

Em relação à esterilização dos instrumentais, antes da ação, $100 \%$ dos estudantes faziam sempre e após esse número reduziu para 98,8\%. Estudos 
também mostraram que a esterilização ocorre em torno de $98 \%$ a $99,1 \%{ }^{1,4}$. Em um estudo no estado do Rio de Janeiro, mais de $60 \%$ dos estudantes e cirurgiões-dentistas realizam a esterilização como um dos métodos de evitar a contaminação cruzada $^{20}$. A esterilização deve ser realizada em todos os artigos que entram em contato com o sistema vascular ou membranas mucosas, pois promove a eliminação ou destruição completa de todas as formas de microrganismos presentes, inclusive esporos bacterianos ${ }^{19,21}$.

Sobre o conhecimento em biossegurança, antes da ação, 53,6\% dos alunos responderam que conheciam as normas e após a ação, apenas 44,0\%. No estudo de Schroeder et al., (2010) $^{9}, 75,35 \%$ dos estudantes possuíam conhecimento sobre as normas de biossegurança e somente $9,15 \%$ as desconheciam.

No que se refere à principal fonte de conhecimento sobre biossegurança, antes da ação, dos 323 entrevistados, 287 (88,9\%) responderam que era a Faculdade de Odontologia e após a ação, dos 325 entrevistados, 297 (91,4\%). Souza et al., $(2017)^{22}$ demonstraram que os estudantes do curso de Odontologia da Universidade Federal de Pernambuco são favoráveis às redes sociais como meios de estudo da Biossegurança, tais como o Facebook (94,3\%), o Whatsapp (100\%) e o Instragram $(88,7 \%)$.

Ainda que não tenha sido realizada nenhum tipo de ação educativa voltada aos docentes, houve melhoria. Antes da ação, 85,5\% dos alunos relataram que os docentes da Faculdade não faziam considerações sobre biossegurança na clínica. Após a ação esse número diminuiu e 76,8\% responderam que não havia orientação (cobrança).

Os dados encontrados neste estudo podem estar relacionados com a proximidade da oferta do conteúdo de Biossegurança nos períodos iniciais do curso de Odontologia da Universidade Federal de Minas Gerais, ou ainda, que esse conteúdo poderia ser mais monitorado pelos docentes.

\section{CONCLUSÃO}

Nesse estudo observou-se que os estudantes da Faculdade de Odontologia da Universidade Federal de Minas Gerais, em seus períodos iniciais, aderem com maior frequência às normas de biossegurança quando comparados aos alunos dos últimos períodos. Dentre os EPI analisados, os óculos são os itens menos utilizados pelos estudantes. $\mathrm{O}$ conhecimento sobre biossegurança não foi satisfatório para o controle da infecção, mesmo após a ação educativa. Estes dados apontam para a necessidade de maior controle e efetividade da aplicação das normas e princípios da biossegurança na faculdade, que tem um importante papel na orientação e monitoramento dos alunos para garantir que as normas de biossegurança sejam implementadas no cotidiano das atividades clínicas, assegurando a proteção e qualidade do atendimento odontológico.

\section{ABSTRACT \\ Biosafety in Dentistry: conduct of students before and after an educational intervention}

The objective of this study was to evaluate the knowledge of and adherence to biosafety and infection control norms of dental students. This was a cross-sectional descriptive study carried out with students from 4th to 10th semester, enrolled in the second half of 2017. An educational intervention to reinforce biosafety knowledge was implemented through the distribution of information flyers to students and poster placement in areas of high pedestrian circulation. Sociodemographic and biosafety information was collected before and after the intervention using a validated questionnaire. Descriptive and bivariate analyses were performed with the chi-square test using SPSS software, version 19. The research was approved by the Research Ethics Committee. The sample consisted of 653 students, most of them female, between the 7 th and 10th semesters, with a mean 
age of 22.6 years. Before and after the intervention, more than $80 \%$ always used physical protection barriers. The frequency of environment disinfection and use of personal protection equipment decreased after the intervention. Always performing instrument washing increased from $95.4 \%$ to $96.6 \%$ after the intervention, while sterilization decreased from $100 \%$ to $98.8 \%$. There was an association between the use of personal protection equipment with being women and with semester ( $p<0.001$ ). We conclude that students in initial semesters more often adhere to biosafety standards. Knowledge about biosafety was not satisfactory for infection control even after the educational intervention.

Descriptors: Infection Control. Containment of Biohazards. Teaching. Sterilization. Personal Protective Equipment.

\section{REFERÊNCIAS}

1. Engelmann AI, Daí AA, Miura CSN, Bremm LL, Boleta-Ceranto DCF. Avaliação dos procedimentos realizados por cirurgiões-dentistas da região de CascavelPR visando ao controle da biossegurança. Odontol Clín-Cient. 2010;9(2):161-5.

2. Xerez JE, Neto HC, Júnior FL, Maia CA, Galvão HC, Górdon-Núñez MA. Perfil de Acadêmicos de Odontologia sobre Biossegurança. Rev Fac Odontol Porto Alegre. 2012;53(1):11-5.

3. Oliveira JS, Nery AA, Morais RLGL, Robazzi MLCC. Acidentes com perfurocortante entre trabalhadores de saúde. Rev APS. 2015;18(1):108-15.

4. Pimentel MJ, Filho MMVB, Santos JP, Rosa MRD. Biossegurança: comportamento dos alunos de Odontologia em relação ao controle de infecção cruzada. Cad Saúde Colet. 2012;20(4):525-32.

5. Gomes LC, Miguel YD, Rocha TC, Gomes
EC. Biossegurança e resíduos de serviços de saúde no cotidiano acadêmico. Rev Ciênc Farm Básica Apl. 2014;35(3):443-50.

6. Bezerra ALD, Sousa MNA, Feitosa ANA, Assis EV, Barros CMB, Carolino ECA. Biossegurança na odontologia. ABCS Health Sci. 2014;39(1):29-33.

7. Lima AA, Azevedo AC, Fonseca AGL, Silva JLM, Padilha WWN. Acidentes Ocupacionais: Conhecimento, Atitudes e Experiências de Estudantes de Odontologia da Universidade Federal da Paraíba. Pesqui Bras Odontopediatria Clín Integr. 2008;8(3):327-32.

8. Martins LS. Biossegurança: avaliação do conhecimento e aderência dos estudantes de odontologia da UFMG em relação ao controle de infecção [trabalho de conclusão de curso]. Belo Horizonte: Faculdade de Odontologia, Universidade Federal de Minas Gerais; 2016.

9. Schroeder MDS, Marin C, Miri F. Biossegurança: grau de importância na visão dos alunos do curso de graduação de Odontologia da Univille. RSBO. 2010;7(1):20-6.

10. Miotto MHMB, Rocha RM. Acidente ocupacional por material perfurocortante entre acadêmicos de odontologia. Rev Bras Promoç Saúde. 2012;25(1):97-102.

11. Arantes DC, Hage CA, Nascimento LS, Pontes FSC. Biossegurança aplicada à Odontologia na Universidade Federal do Pará, Cidade de Belém, Estado do Pará, Brasil. Rev Pan-Amaz Saúde. 2015;6(1):118.

12. Diniz DN, Carvalho CM, Costa LJ, Pereira MSV, Albuquerque ACL, Silva DF. Conhecimento dos Alunos do Curso de Graduação em Odontologia da Universidade Estadual da Paraíba sobre Hepatites Virais. Pesqui Bras Odontopediatria Clín Integr. 
2011;11(1):117-21.

13. Lages SMR, Santos AFS, Silva Junior FF, Costa JG. Formação em Odontologia: O Papel das Instituições de Ensino na Prevenção do Acidente com Exposição a Material Biológico. Ciênc Trab. 2015;17(54):182-7.

14. Comissão de Biossegurança da Faculdade de Odontologia da UFMG: Controle de infecção em Odontologia: manual de normas e rotinas técnicas. COBIO; 2003.

15. Agência Nacional de Vigilância Sanitária: Serviços Odontológicos: prevenção e controle de riscos. Brasília: ANVISA; 2006.

16. Wood AJ, Nadershashi NA, Fredekind RE, Cuny EJ, Chambers DW. Student occupational exposure incidence: perception versus reality. J Dent Educ. 2006;70 (10):1081-8.

17. Tura F, Alves CFS, Kirsten VR, Amaral CF, Dotto PP, Santos RCV. Avaliação da contaminação interna em canetas de alta rotação na prática clínica. Braz Dent Sci. 2011;14(3/4):18-26.

18. Russo EMA, Carvalho RCR, Lorenzo JL, Garone Netto N, Cardoso MV, Grossi E. Avaliação da intensidade de contaminação de pontas de seringa tríplice. Pesqui Odontol Bras. 2000;14(3):243-247.
19. Universidade de São Paulo; Faculdade de Odontologia de Bauru. Manual de Biossegurança. $2^{\text {a }}$ ed. Bauru:USP; 2015.

20. Silva GS, Almeida AJ, Paula VS, Villar LM. Conhecimento e utilização de medidas de precaução-padrão por profissionais de saúde. Esc Anna Nery Rev Enferm. 2012;16(1):103-10.

21. Comissão de Biossegurança do Centro Universitário Cesmac: Manual de Biossegurança: Odontologia. CESMAC; 2015.

22. Souza FB, Lopes MGQ, Lima Filho RM. Redes sociais na aprendizagem em odontologia: opinião dos estudantes de uma universidade brasileira. Rev Cubana Estomatol. 2017;54(2).

\section{Correspondência para:}

Lorrany Gabriela Rodrigues

e-mail: lorranygrodrigues@gmail.com

Rua Jornalista Wilson Angelo, 71/03 São Luiz 31.310-220 Belo Horizonte/MG 